\title{
Delivery of riboflavin-5'-monophosphate into the cornea: can liposomes provide any enhancement effects?
}

Article

Accepted Version

Creative Commons: Attribution-Noncommercial-No Derivative Works 4.0

Kandzija, N. and Khutoryanskiy, V. V. (2017) Delivery of riboflavin-5'-monophosphate into the cornea: can liposomes provide any enhancement effects? Journal of Pharmaceutical Sciences, 106 (10). pp. 3041-3049. ISSN 0022-3549 doi: https://doi.org/10.1016/j.xphs.2017.05.022 Available at https://centaur.reading.ac.uk/70563/

It is advisable to refer to the publisher's version if you intend to cite from the work. See Guidance on citing.

Published version at: http://www.sciencedirect.com/science/article/pii/S0022354917303799

To link to this article DOI: http://dx.doi.org/10.1016/j.xphs.2017.05.022

Publisher: Elsevier

All outputs in CentAUR are protected by Intellectual Property Rights law, including copyright law. Copyright and IPR is retained by the creators or other copyright holders. Terms and conditions for use of this material are defined in the End User Agreement.

www.reading.ac.uk/centaur 
Central Archive at the University of Reading

Reading's research outputs online 


\title{
Delivery of riboflavin-5'-monophosphate into the cornea: can liposomes provide any enhancement effects?
}

\author{
Neva Kandzija, Vitaliy V. Khutoryanskiy* \\ Reading School of Pharmacy, University of Reading, Reading, Berkshire, RG6 6AD, UK \\ *Corresponding author: \\ Tel.: +441183786119 \\ E-mail address: v.khutoryanskiy@reading.ac.uk (Prof V.V. Khutoryanskiy)
}

\begin{abstract}
Keratoconus is a progressive condition caused by the thinning of the cornea, which eventually deforms the front surface of the eye into a cone shape leading to ghosting, multiple images, glare and several other vision problems. Currently keratoconus is treated with UV-induced riboflavin-mediated collagen cross-linking, which requires a physical removal of the corneal epithelium under topical anesthesia. This study reports the penetration of riboflavin $(\mathrm{Rb})$ and its more water-soluble form, riboflavin-5'- monophosphate ( $\mathrm{RbP})$, into the bovine cornea ex vivo. Using ex vivo bovine corneal tissues and $0.8 \mathrm{mg} / \mathrm{mL}$ drug solutions in phosphate buffer, it was established that $\mathrm{RbP}$ penetration into the cornea within 3 hours of diffusion experiment was greater $(17.3 \pm 0.8 \mu \mathrm{g})$ compared to $\mathrm{Rb}$ $(10.4 \pm 4.2 \mu \mathrm{g})$. In the cornea $\mathrm{RbP}$ was found to convert to $\mathrm{Rb}$, which is mediated with enzymes present in this tissue. Several formulations including the conventional and propylene glycol-containing liposomes with encapsulated RbP have been developed and their effect on the drug penetration into the bovine cornea was evaluated. Encapsulation of RbP into the liposomes did not provide any statistically significant improvement in the penetration of RbP into the cornea.
\end{abstract}

Keywords: Keratoconus, Riboflavin, Cornea, Liposomes, Ocular drug delivery 


\section{Introduction}

Keratoconus is a progressive condition caused by the thinning of the cornea, which eventually deforms the front surface of the eye into a cone shape, and can lead to ghosting, multiple images, glare and several other vision problems. It is the most common dystrophy of the cornea and according to recent estimates, 1 in 2000 people worldwide suffer from keratoconus [1]. Wollensak et al. [2] suggested a novel approach for treating keratoconus using ultraviolet-induced riboflavin-mediated collagen cross-linking (CXL) of the corneal stroma (Fig.1). In this procedure a riboflavin-5'- monophosphate $(\mathrm{RbP})$ solution is applied to the eye and activated via UVA irradiation $(370 \mathrm{~nm})$, where it acts as a photosensitiser. During collagen cross-linking, RbP generates singlet oxygen species, which induce the formation of covalent bonds between collagen molecules, while riboflavin additionally protects the cornea from the damage from UVA radiation [3]. CXL treatment has been proven successful in strengthening and stabilizing the cornea since its biomechanical properties are primarily determined by the collagen fibers.

However, in order to achieve efficient penetration of $\mathrm{RbP}$ into the corneal tissue, it is currently necessary to remove the corneal epithelium under topical anesthesia. Common side effects of epithelial abrasion include pain, corneal edema, and mild stromal haze $[4,5]$. Therefore, finding a way to improve delivery of the drug without epithelial abrasion would significantly simplify the treatment, speed up the recovery, and improve patient compliance.

There are two forms of this photosensitive drug, a hydrophilic ionic RbP that is currently used clinically in corneal cross-linking, and a less polar non-ionic riboflavin $(\mathrm{Rb})$ with a lower solubility in water. In previous studies various approaches have been considered to deliver riboflavin to the cornea including the use of permeation enhancers such as $\mathrm{Ca}^{2+}$ sequestering compounds, which showed improvements in the permeability of $\mathrm{Rb}$ when applied on the intact epithelial barrier due to loosening of tight junctions [1, 6]. Morrison et al. [7] reported that it is also possible to both increase the solubility and enhance the corneal permeability of $\mathrm{Rb}$ with the use of $\beta$ cyclodextrin. Recently, Bottos et al. [8] demonstrated that with Rb- and RbP-based nanoemulsions it is possible to saturate the stroma with the concentration of the drug comparable to the levels required during the standard epithelium-off procedure. However, these nanoemulsions were able to show the comparable results only after 4 hours. Other attempts to enhance the corneal permeability of the drug involved Rb-loaded mucoadhesive films [9], preparation of water-dilutable microemulsions with $\mathrm{RbP}$ [10], use of ultrasound with $\mathrm{Rb}$ [11] and iontophoresis with 
RbP [12]. Despite all the efforts, the efficacy of CXL treatment has still not been sufficiently improved and, therefore, the enhancement of transepithelial absorption of riboflavin remains an important issue.

One of the potential strategies to improve corneal permeability of the drug applied to the eye is the use of liposomal formulations. Liposomes are phospholipid vesicles with the size range of $20 \mathrm{~nm}$ to $15 \mu \mathrm{m}$. Their specific structure enables encapsulation of different active substances without chemical bonding or any prior chemical modifications. Hydrophilic drugs are entrapped in the inner aqueous phase or are electrostatically bound to the outer bilayer. Lipophilic drugs interact with the lipid region, and amphipathic molecules are deployed between these two regions. Due to their biodegradability, biocompatibility, non-toxicity and non-immunogenicity, liposomes have shown some advantages among several other drug delivery systems $[11,12]$. Research has shown improvement in precorneal drug retention, transcorneal permeation and therapeutic efficacy when liposomes are administered topically on the surface of the eye $[11,13]$.

The use of liposomes could potentially be considered as a viable strategy to overcome the epithelial barrier and improve riboflavin permeability into the corneal stroma for the treatment of keratoconus. Therefore, in this work the conventional and propylene glycol-containing liposomes (PG) with riboflavin-5'-monophospahte have been developed and the transcorneal drug penetration was evaluated in vitro. Propylene glycol is currently used in ophthalmic solutions present on the market (Systane $\left.{ }^{\circledR}\right)$ as a lubricant to treat patients with mild to moderate dry eye syndrome $[14,15]$. The potential of conventional liposomes to increase in vitro corneal flux was already reported in the literature [18]. Additionally, PG liposomes were studied in transdermal and vaginal drug delivery and reported to provide some advantages such as smaller size diameter and higher encapsulation efficacy resulting in enhanced permeability of drugs through the skin [19]. 


\section{Materials and methods}

\subsection{Materials}

Lipoid S100 (soybean lecithin, >94 \% phosphatidylcholine) and Lipoid S75 (soybean lecithin with $70 \%$ phosphatidylcholine) were generously provided by Lipoid GmbH (Ludwigshafen, Germany). Riboflavin-5'monophosphate $(\mathrm{RbP})$, riboflavin $(\mathrm{Rb})$, egg phosphatidylcholine (EPC), propylene glycol, sodium hexane-1sulfonate monohydrate and glacial acetic acid were purchased from Sigma-Aldrich (Gillingham, UK). Sephadex G50 superfine was obtained from GE Healthcare (UK). Sodium chloride, potassium chloride, sodium phosphate, potassium dihydrogen phosphate, Minisart syringe filters $(0.2 \mu \mathrm{m})$ and HPLC grade ethanol were purchased from Fischer Scientific (Hemel Hempstead, UK). Water used for all aqueous solutions was purified using a Milli-Q system. All other chemicals and reagents were of analytical grade or superior.

Phosphate buffer, $\mathrm{pH} 7.4$, and ion pair buffer were prepared according to procedures reported by Morrison et al. [20], and Anyakora et al. [21]. Ion pair buffer, used as a mobile phase, was prepared by dissolving $1.8822 \mathrm{~g}$ sodium hexane-1-sulfonate monohydrate in 2 liters of ultrapure water and adjusted to $\mathrm{pH} 3.0 \pm 0.2$ using glacial acetic acid. Phosphate buffer, used for Franz diffusion measurements, was prepared by mixing $8.0 \mathrm{~g} \mathrm{NaCl}, 0.2 \mathrm{~g}$ $\mathrm{KCl}, 1.44 \mathrm{~g} \mathrm{Na}_{2} \mathrm{HPO}_{4}$ and $0.24 \mathrm{~g} \mathrm{KH}_{2} \mathrm{PO}_{4}$ with demineralised water (total volume $1000 \mathrm{~mL}$ ).

\subsection{Preparation of liposomes}

In order to optimise entrapment efficacy of RbP, different types of lipids were used according to two methods of preparation (Table 1). The RbP content was kept constant in all preparations as well as liposomal suspension volume $(5 \mathrm{~mL})$.

The first method that was used for the preparation of liposomes was "polyol dilution method", reported by Vanic et al. [19]. Lipid phase was prepared by dissolving phosphatidylcholine from egg (EPC) or soybeans (S75 or $\mathrm{S} 100)$ in $1 \mathrm{~g}$ of propylene glycol at $60{ }^{\circ} \mathrm{C}$ under continuous stirring. $1 \mathrm{~mL}$ of $\mathrm{RbP}$ solution $(50 \mathrm{mg} / \mathrm{mL})$ was added to form an initial pro-liposome mixture. Liposomal suspension was diluted by the dropwise addition of water until the final volume of $5 \mathrm{~mL}$.

The second method used for liposomal preparation was the conventional "film method". Phospholipids were dissolved in ethanol in a round-bottom flask. Organic solvent was then completely removed with the rotary vacuum evaporator (Rotavapor ${ }^{\circledR}$ R-124, Buchi, Switzerland). After the thin film was formed at the bottom of the flask, $5 \mathrm{~mL}$ of RbP solution $(10 \mathrm{mg} / \mathrm{mL})$ was added and was hand shaken for 20 minutes.

All the preparations were stored in a refrigerator $\left(4-8{ }^{\circ} \mathrm{C}\right)$ overnight prior to vesicle size reduction. The liposomal formulations were extruded three times through $800-\mathrm{nm}$ polycarbonate membrane filter (Whatman ${ }^{\circledR}$ Nuclepore $^{\mathrm{TM}}$, Whatman International LTD, England) followed by three times extrusion through 200 -nm membrane using Avanti mini extruder. 


\subsection{Particle size analysis and zeta potential measurements}

Measurements of particle diameter, polydispersity index and zeta potential were conducted using Zetasizer Nano-ZS (Malvern Instrument, UK). The mean diameter and polydispersity index were measured by dynamic light scattering, while for the zeta potential measurements laser doppler micro-electrophoresis was used. Prior to data collection, samples were diluted with an appropriate amount of water, which was previously filtered through $200 \mathrm{~nm}$ Minisart filters. Each sample was measured three times at $25^{\circ} \mathrm{C}$ and the mean value \pm standard deviation was calculated. Before the measurements were performed, all liposomal formulations were sonicated for approximately $15 \mathrm{~s}$ in a sonication bath (F5200b, Decon Laboratories Limited, UK).

\subsection{Entrapment efficacy}

In order to determine the entrapment efficacy of liposomes containing RbP, non-encapsulated drug was separated from lipid vesicles by size exclusion chromatography according to the minicolumn centrifugation procedure [22]. Spin columns were placed in standard $1.5 \mathrm{~mL}$ Eppendorf vial and filled with $700 \mu \mathrm{L}$ of Sephadex G50 previously hydrated with demineralised water. Minicolumns were centrifuged at $200 \mathrm{~g}$ for 1 minute in order to remove water from Sephadex bed. $100 \mu \mathrm{L}$ of PBS was added on the top of the bed and centrifuged for 2 minutes at 200g. This step was repeated twice. Once Sephadex gel was dry, spin columns were transferred to new Eppendorf vial and $0.1 \mathrm{~mL}$ of each liposomal suspension was added to the top. Subsequently, the columns were spun again at $200 \mathrm{~g}$ to separate liposomal formulation from the free drug [22]. The eluates with liposomes were kept for HPLC analysis. Prior to HPLC assay lipid bilayer was disrupted with methanol. Free drug was recovered by washing the column with water and eluting by centrifugation at $600 \mathrm{~g}$ [23]. The percentage of entrapped RbP was calculated using the following equation:

$$
E E \%=\frac{W_{\text {total }}-W_{\text {free }}}{W_{\text {total }}} \times 100,
$$

where EE is the entrapment efficacy; $\mathrm{W}_{\text {total }}$ represents the amount of the total drug, and $\mathrm{W}_{\text {free }}$ is the amount of nonencapsulated drug. This method of EE determination is commonly used in the literature for determining drug entrapment efficiency into liposomes; however, it has some limitations and can overestimate the results.

\subsection{Permeability measurements}

\subsubsection{Comparative study of $\mathrm{Rb}$ and $\mathrm{RbP}$ penetration into and permeability through the bovine cornea}

In this study the penetration of $\mathrm{Rb}$ and $\mathrm{RbP}$ into and permeability through the cornea was compared using experiments with Franz diffusion cells. Rb and RbP solutions were prepared in PBS at $0.8 \mathrm{mg} / \mathrm{mL}$. Dissected bovine corneas $(n=6)$ were mounted between donor and receiver chamber. The receptor compartment was filled with PBS $(16.5 \mathrm{~mL})$, ensuring no air bubbles were trapped under the cornea, and $1 \mathrm{~mL}$ of $\mathrm{Rb}$ or $\mathrm{RbP}$ was added to the donor chamber, which was then covered with a cling film to prevent evaporation. All apparatus were placed in water bath at $34{ }^{\circ} \mathrm{C}$ to mimic the physiological temperature at the cornea. Aliquots from the donor compartment were taken for HPLC analysis at the beginning of each experiment and after 3 hours to determine the amount of drug that went into 
and through the cornea. Results are expressed in \% as the mass difference at the beginning and at the end of the experiment. Additionally, after 3 hours of the diffusion experiment the aliquots were taken from the receptor compartment and analyzed. In order to determine the drug penetration into the tissue, the exposed part of the cornea was cut after each experiment, weighed and placed in a vial with $3 \mathrm{~mL}$ mixture of ethanol : water $=1: 1$ (by volume). After three days, $1 \mathrm{~mL}$ of the corneal extract was filtered through $0.2 \mu \mathrm{m}$ syringe filter and the HPLC analysis was performed. The calculation of the drug amount was performed using a calibration curve prepared with a series of riboflavin standard solutions. The results are expressed as micrograms of $\mathrm{Rb} / \mathrm{RbP}$ per mass of the cornea in grams. The experiments were conducted in triplicates, and samples were covered with aluminum foil to exclude light-induced degradation.

\subsubsection{In vitro penetration study of $\mathrm{RbP}$ encapsulated into the liposomes}

Although Franz diffusion cells are considered to be industry standard for permeability tests in vitro, problems caused by corneal swelling were reported previously [1]. Therefore, for the permeation studies of liposomal samples, the "whole eye" method was used (Fig. 1s, Supplementary Information). Briefly, the bovine eye was placed in bottle lids with the corneas facing up. Then Franz diffusion donor chamber was added at the top of the bovine eye and everything was secured with a cling film and placed in a water bath at $34{ }^{\circ} \mathrm{C}$. To study the permeation of riboflavin into the cornea, $0.5 \mathrm{~mL}$ of liposomal preparation or control solution $(10 \mathrm{mg} / \mathrm{mL}$ of $\mathrm{RbP})$ was added in the donor chamber. After $1.5 \mathrm{~h}$, the exposed part of the cornea was cut, weighed and placed in a vial with $3 \mathrm{~mL}$ mixture of ethanol : water $=1: 1$ (by volume). After three days, $1 \mathrm{~mL}$ of the corneal extract was filtered through $0.2 \mu \mathrm{m}$ syringe filter and HPLC analysis was performed. All the experiments were conducted in triplicates, and samples were protected from light with aluminum foil.

\subsection{HPLC analysis}

Concentrations of riboflavin-5'-monophosphate and riboflavin were determined by HPLC method according to the procedure reported by Morrison et al. [1]. Quantitation was achieved with run time of 10 minutes in the isocratic conditions using the mobile phase consisting of $20 \%$ ethanol and $80 \%$ ion pair buffer at $0.8 \mathrm{~mL} / \mathrm{min}$ $\left(30{ }^{\circ} \mathrm{C}\right.$ ). Stationary phase was Hamilton PRP-1 $\mathrm{C}_{18}$ column, $150 \mathrm{~mm} \times 4.6 \mathrm{~mm}, 5 \mu \mathrm{m}$ (part number: 79425 ). The analyses were carried out using fluorescence detector with the excitation wavelength of $450 \mathrm{~nm}$ and emission wavelength of $523 \mathrm{~nm}$. The injection volume was $0.1 \mu \mathrm{L}$, and data acquisition was done via Peaksimple (version 4.09, SRI Inc., USA). RbP peak was found to have the retention time of 1.8 minutes, whereas riboflavin peak appeared at 5.3 minutes. The method was validated presenting a linear calibration curve (for $\mathrm{Rb}: \mathrm{R}^{2}=0.9998$, $\mathrm{y}=1087.1 \mathrm{x}-98.515$; and for $\mathrm{RbP}: \mathrm{R}^{2}=0.9953, \mathrm{y}=21347 \mathrm{x}-35.852$ ) over a drug concentration range of 0.00125 to $0.04 \mathrm{mg} / \mathrm{mL}$ for $\mathrm{Rb}$ and 0.00625 to $0.5 \mathrm{mg} / \mathrm{mL}$ for $\mathrm{RbP}$, respectively. 


\subsection{Statistical analysis}

Statistical analyses were performed using the statistical programming language $R$ within the RStudio environment (version 0.98.1091, RStudio Inc., USA). Analyses of means of two groups were performed using the independent two-sample Student's t-test; group means were considered significantly different when $\mathrm{P}<0.05$, and annotated in figures with $(*)$, while the tests which resulted in values of $\mathrm{P}<0.01$ were annotated as $(* *)$. When comparing three or more groups, one way between subjects ANOVA was first used to establish if statistically significant differences exist between group means. $\mathrm{P}<0.05$ was considered statistically significant, and further posthoc analysis was performed using pairwise t-tests with the Bonferroni correction method to adjust for multiple comparisons problem: if a total of $m$ pair-wise ad-hoc tests were performed, then $\mathrm{P}<0.05 / m$ was required to consider the means of the two compared groups statistically significant [24].

\section{Results and discussion}

\subsection{Comparative study of $\mathrm{Rb}$ and $\mathrm{RbP}$ penetration into the bovine cornea}

The goal of this study was to develop a formulation which would achieve a desired concentration of riboflavin in the corneal stroma without the need for removal of the epithelium. The cornea represents the most significant barrier for absorption of drugs into the eye. The reasons for poor drug absorption by the cornea are twofold: a small absorption surface area $\left(\sim 1 \mathrm{~cm}^{2}\right)$ and its complex multilayered structure [25]. The cornea is composed of five main layers: the epithelium, Bowman's layer, the stroma, Descemet's membrane and the endothelium. Corneal drug absorption is influenced by drug characteristics such as lipophilicity, pKa value and molecular size [26]. Among these properties the octanol/buffer partition coefficient $(\log \mathrm{P})$, which represents the measure of lipophilicity, has been researched most extensively. It is reported that the preferred partition coefficient for corneal drug absorption is between 10 to 100, suggesting that lipophilic drugs are favored in corneal transport [27]. This is due to lipophilic nature of corneal epithelium, which represents a barrier to around $90 \%$ of hydrophilic drugs [1]. Following ocular administration, the drugs with high partition coefficient will be quickly absorbed by the cornea. However, corneal permeability of molecules with low polarity is limited by the stroma, the hydrophilic inner layer of the cornea, and generally low amount of drug is expected to reach the aqueous humour of the eye [27]. Taking this into account, it could be expected that a less polar $\mathrm{Rb}(\log \mathrm{P}=-0.92$ [28]) should have a higher penetration through the corneal epithelium compared to more hydrophilic $\mathrm{RbP}(\log \mathrm{P}=-1.20$ [29]).

The penetration of both $\mathrm{Rb}$ and $\mathrm{RbP}$ into the bovine cornea was studied in this work using two methods of analysis. First, the total penetration was calculated based on the difference between the initial drug content in the donor compartment of Franz diffusion cell (FDC) at the beginning of each experiment and the amount left after three hours of its diffusion into the cornea. Second, the amount of riboflavin extracted from the cornea after completion of the FDC experiment was also evaluated. The amounts of $\mathrm{RbP}$ and $\mathrm{Rb}$ penetrated into the cornea within 3 hours are shown in Fig.2a. In contrast to our expectations, the total amount of RbP penetrated into the cornea was significantly higher compared to $\mathrm{Rb}(p<0.05$, Student's t-test). After 180 minutes, $17.3 \pm 0.8 \mu \mathrm{g}$ of $\mathrm{RbP}$ was delivered into the cornea, and during the same time, the total permeation of $\mathrm{Rb}$ was $10.4 \pm 4.2 \mu \mathrm{g}$. It should be 
noted that HPLC analysis of the receiver compartment did not show any presence of Rb or RbP, indicating that there was practically no drug permeation through the cornea during this time and the entire drug penetrated into the cornea remains in this tissue.

Fig. $2 \mathrm{~b}$ shows the measurements of the amount of the drugs extracted from the cornea. The amount of $\mathrm{Rb}$ extracted from the treated corneas was $0.08 \pm 0.05 \mu \mathrm{g}$ compared to $0.05 \pm 0.03 \mu \mathrm{g}$ of $\mathrm{RbP}$; there was no statistically significant difference between $\mathrm{Rb}$ and $\mathrm{RbP}(p>0.05)$. The levels of $\mathrm{Rb}$ and $\mathrm{RbP}$ absorbed by the corneas in this experiment were according to our expectations, since $\mathrm{Rb}$ is lipophilic and this resulted in easier penetration of the epithelium.

Possible explanation for the lower levels of $\mathrm{Rb}$ when measuring the total permeability could be the lack of correlation between partition coefficient and drug permeability rate as observed by Grass and Robinson [27]. It was observed that for the drugs with partition coefficient in the range of -1 to 0 the increase in $\log P$ value did not result in increase of corneal permeability. We assume that lower hydrophilicity of $\mathrm{Rb}$ would lead to its accumulation in the cornea. This assumption seems to be consistent with the work by Bottos et al. [8], which reported that Rb cannot be retained in the corneal stroma due to its lipophilic nature in contrast to its more hydrophilic counterpart - RbP. Furthermore, Prausnitz \& Noonan [30] reported a comprehensive database of permeability measurements of the endothelium, stroma, epithelium, and other ocular tissues. Their study analysed more than 300 measurements from 40 different studies, and discussed the penetration of lipophilic and hydrophilic drugs through the eye. Even though the epithelium does represent a significantly stronger barrier for hydrophilic molecules, the study did not provide a definite conclusion on the impact of the endothelium on lipophilic molecules, while it did state that the endothelium does not present a significant barrier for hydrophilic compounds.

\subsection{Conversion of $R b P$ to $R b$ in the cornea}

The analysis of $\mathrm{RbP}$ and $\mathrm{Rb}$ penetration into the cornea allowed us to establish a conversion of $\mathrm{RbP}$ into $\mathrm{Rb}$ mediated by enzymes present in the cornea. As shown in Fig.3, the typical HPLC chromatogram of RbP shows two peaks. The first peak was found to appear after 1.8 minutes $\left(\mathrm{t}_{\mathrm{r}}=1.8 \mathrm{~min}\right)$ and it corresponds to $\mathrm{RbP}$, while the second peak belongs to $\mathrm{Rb}$, with the retention time of 5.3 minutes $\left(\mathrm{t}_{\mathrm{r}}=5.3 \mathrm{~min}\right)$. This is in agreement with prior work by Lam and Lowande [32], where the composition of $70 \%$ riboflavin-5'-phosphate sodium salt was shown to be a mixture of $10 \%$ riboflavin and $60 \%$ phosphate salt. It is well known that RbP is converted to $\mathrm{Rb}$ by acidic or alkaline phosphatases due to its structural similarity to the nucleosides [32]. In order to confirm that this is happening in the cornea during the permeability test, the RbP solution was mixed with the homogenized parts of the cornea and its concentration was measured after 2 hours using HPLC. In comparison to their initial values (Fig.4), the concentration of $\mathrm{RbP}$ was reduced by $75 \%$, while the concentration of $\mathrm{Rb}$ increased by $12 \%(p<0.05, \mathrm{n}=3)$.

To confirm the role of enzymes in $\mathrm{RbP}$ conversion into $\mathrm{Rb}$, the measurements were also carried out with the homogenized cornea, which was autoclaved for 30 minutes at $121^{\circ} \mathrm{C}$ to ensure that enzymes lost their activity. 
Again, the RbP solution was added, and samples were taken for HPLC analysis after one hour. Fig.2s (Supplementary information) shows no increase in the concentration of $\mathrm{Rb}$ after 2 hours compared to time zero. This suggests that the increase in the content of $\mathrm{Rb}$ is caused by conversion of RbP mediated by corneal enzymes.

Additional control experiment was conducted, where $\mathrm{RbP}$ solution was left for two hours at $37{ }^{\circ} \mathrm{C}$ and room temperature. No significant differences in the concentrations of $\mathrm{Rb}$ or $\mathrm{RbP}$ were found after two hours compared to the initial values (data not shown). Therefore, we assume that conversion of $\mathrm{RbP}$ to $\mathrm{Rb}$ is mainly caused by the corneal enzymes. This finding is important for better understanding of the processes taking place in the cornea, as well as for RbP detection during drug permeation tests through the cornea.

\subsection{Preparation and characterisation of liposomes with $\mathrm{RbP}$}

Liposomal formulations of riboflavin were previously studied in tumor targeting and were reported to achieve improvements in riboflavin's photostabilization [33,34]. However, to the best of our knowledge, there is no report in the literature on how incorporation of RbP into liposomal carriers will affect the transcorneal permeation of this drug. The main reason to investigate the potential improvement of RbP permeability through the eye after encapsulation in the liposomes, instead of investigating $\mathrm{Rb}$, was the clinical relevance since $\mathrm{RbP}$ is currently predominantly used in the treatment of keratoconus. Furthermore, $\mathrm{RbP}$ has higher aqueous solubility, which allowed us to prepare more concentrated solutions and to achieve higher total corneal permeability as observed in earlier parts of the present work.

While developing liposomes containing RbP, our first objective was to optimise their composition. It is well known that composition of liposomes influences their size, polydispersity index, and charge - parameters that affect the performance of liposomes as an ocular drug delivery system. Therefore, in this study different classes of liposomes were developed. Conventional liposomes were prepared using "film method" and propylene glycolcontaining liposomes (PG) were formed using "polyol dilution method". Liposomal formulations were prepared using three different types of phospholipids at different concentrations but keeping the amount of RbP equal in all preparations. Since egg and soybean lecithin are natural phospholipids widely used in ocular drug delivery, liposomes in the present study were formed using these phospholipids [13]. The composition and results obtained from physicochemical analysis are summarised in Table 1. 


\subsubsection{Size and polydispersity index of non-extruded liposomes}

Firstly, we measured the size of the particles of the original liposomal preparation, before the extrusion was undertaken. Data obtained from this analysis are in agreement with other research in this field, further supporting the statement that liposomes prepared with "conventional film method" are larger in diameter (between $2156 \pm 345$ and $6837 \pm 1602 \mathrm{~nm}$ )[19]. On the other hand, liposomes prepared by "polyol dilution method" were smaller in size (between $496 \pm 13$ and $1838 \pm 184 \mathrm{~nm}$ ). One-way ANOVA reports statistically significant differences between group means $(p<0.05)$. Statistically significant differences were observed for both FM-EPC-100 and PD-S100-300 in comparison with PD-S75-300 liposomes. No statistically significant difference was found between FM-EPC-100 and PD-S100-300. These results are in agreement with recent studies published by Elmoslemany et al. [35], who suggested that interactions between propylene glycol and phospholipids increase liposomal flexibility and decrease the size of the particles $[30,19]$.

Another parameter influencing the size of the vesicles is the lipid charge. According to the literature charged lipids produce smaller and less lamellar particles [36]. Indeed, ANOVA tests confirm statistically significant difference in sizes $(\mathrm{P}<0.05)$ when liposomes were formed from $\mathrm{S} 75$, which contains negatively charged phospholipids (496 \pm 13 and $540 \pm 9 \mathrm{~nm}$ ), compared to almost neutrally charged S100 (1139 \pm 121 and $1838 \pm 184$ $\mathrm{nm})$.

Furthermore, non-extruded liposomes showed higher values of polydispersity index which indicates that the system has a broad distribution of particle sizes. The polydispersity index is a measure of the size distribution and according to the literature, liposomal formulation is considered to be heterogeneous if the value of polydispersity index is $\geq 0.3$ [37].

\subsubsection{Size and polydispersity index of liposomes after the size reduction}

Since the particle size distribution can influence the permeability of topically applied drugs in ocular drug delivery, all formulations were extruded through 200-nm membrane in order to obtain homogenous size distribution and smaller size (Fig.3s, Supplementary Information). Although the eye can tolerate particles of up to $10 \mu \mathrm{m}$, in order to achieve greater permeability, it is recommended to have particles smaller than $200 \mathrm{~nm}$ [38]. Extrusion resulted in the desired range of vesicles size for the purpose of developed liposomal delivery system. The mean diameter of extruded liposomes was between 130 and $200 \mathrm{~nm}$, with a decrease in polydispersity index value to less than 0.22 . These formulations were used for all further measurements. Our previous study [20] has established that even 27 - $69 \mathrm{~nm}$ silica nanoparticles coated with polyethyleneglycol do not penetrate the intact bovine cornea. Therefore, the penetration of $130-200 \mathrm{~nm}$ liposomes into the cornea is also likely to be hampered. However, the deformable nature of the liposomes could potentially facilitate their permeability. 


\subsubsection{Zeta potential measurements}

Zeta potential measurements are frequently used to describe the stability of the colloidal system [39]. Large negative values of zeta potential $(<-30 \mathrm{mV})$ are expected to result in greater physical stability of the liposomal system due to the repulsion between the charges of the same polarity. This parameter is especially important to consider during the storage of the formulation. Furthermore, charge on the surface might influence its interaction with cells and biological environment [40].

provides the results obtained from zeta potential measurements, which indicate good colloidal stability of the liposomes prepared in this work. Each liposomal formulation with RbP has negative values of zeta potential. It can be seen from the data that more negative values are observed when liposomes were prepared from S75 compared to S100 (ANOVA, $p<0.05$ ). This can be explained with the fact that both phospholipids S75 and S100 do not consist of pure phosphatidylcholine, but they are mixtures of lipids containing negatively charged phospholipids as well. As expected, when liposomes were formed from S100, which has higher content (more than $94 \%$ ) of neutrally charged phosphatidylcholine, low-negatively charged values of zeta potential were observed $(-3 \mathrm{mV})$. However, despite these low values of zeta-potential, these liposomes show excellent colloidal stability, which is confirmed by their small sizes $(126 \pm 1$ and $132 \pm 1 \mathrm{~nm})$ and low values of polydispersity indices $(0.168 \pm 0.008$ and $0.173 \pm 0.007$, respectively). It is believed that colloidal stability of these liposomes is due to the factors other than the surface charge. On the other hand, S75 consists of negatively charged phospholipids resulting in a sharp decrease of zeta potential values $(-47.5 \mathrm{mV})[41]$.

\subsection{Entrapment efficacy}

Entrapment efficacy of the drug into the liposomes is usually influenced by several factors, including drug's partition coefficient, drug's molecular mass, method of their preparation and lipid composition [42]. Studies have shown that hydrophilic drugs have lower encapsulation in the liposomes compared to the encapsulation 
efficacy of the lipophilic drugs [43], which is mainly due to the small volume of the inner aqueous core. Since the $\mathrm{RbP}$ has a $\log \mathrm{P}$ value of -1.20 , we expected low encapsulation levels.

In order to determine the amount of drug encapsulated in the liposomes, the mini-column centrifugation method was used [22]. This method is reported to be advantageous over other methods used for separation of free drug from the liposomes since there is no dilution of liposomal formulation, numerous samples can be analyzed at the same time, and, finally, free drug can be easily recovered in a small volume of water [23]. Fig.4 shows that the encapsulation of RbP was found to be very low for the liposomes prepared by classical "film method". The entrapment efficacy of only 3.5 to $9.6 \%$ is most likely due to aforementioned hydrophilic nature of the drug. On the other hand, the entrapment of 19.9 to $41.8 \%$ of RbP occurred when liposomes were prepared by the "polyol dilution method". These results corroborate the study of Pavelic et al. (2001), which suggested that high entrapment efficacy of hydrophilic drugs using polyol dilution method is a consequence of the first steps of the preparation procedure, where a lipid-polyol solution is exposed to the highly concentrated drug solution [44]. Among the liposomes prepared with polyol dilution method, entrapment efficacy was found to be higher when higher amount of lipid was used.

\subsection{In vitro penetration of $\mathrm{RbP}$ encapsulated into the liposomes}

In the current study we compared the in vitro penetration of RbP encapsulated into the liposomes into the bovine cornea with $10 \mathrm{mg} / \mathrm{mL}$ aqueous solution of the drug. Since the treatment of keratoconus requires the delivery of riboflavin-5'-monophosphate into the corneal stroma, permeability measurements in this study were focused on the penetration into the cornea, as opposed to measuring permeability through the cornea. Hence, after the penetration test was performed using the "whole eye method" [1], the exposed part of the cornea was cut, measured and left in a mixture of ethanol and water in order to extract the absorbed drug from the cornea.

With the same amount of drug per dose, none of the formulations showed statistically significant improvement in ocular penetration of RbP compared to the levels observed in the corneas treated with control solution. Among the used liposomal preparations, the highest corneal drug absorption was observed for the liposomes that were prepared with the conventional film method. Although Fig.5 shows that there was a slight increase in the amount of RbP absorbed by corneas in some measurements for the formulation FM-S75-400, T-test reveals that there is no significant difference compared to the control values in the case of conventional liposomes (ANOVA, $p>0.05$ ). On the other hand, three liposomal formulations prepared with the "polyol dilution method" showed a significantly lower permeation than the control formulation (ANOVA, $p<0.05$ ). In reviewing the literature, similar data was observed in the case of hydrophilic drugs [34, 35]. Singh and Mezei [7, 34] reported that dihydrostreptomycin sulfate encapsulated in liposomes did not show any improvement in its corneal permeation. The authors assumed that this might be explained by the mechanism of interactions between liposomes and surface of the eye. There are four possible ways for liposomes to interact with the cells: adsorption, fusion, lipid exchange and endocytosis. The authors of the aforementioned study suggested that the main interaction between the liposomes 
and the surface of the eye comes from adsorption and lipid exchange, which seems not to be suitable for hydrophilic drugs because of its rapid escape in the surrounding solution. Therefore, the authors emphasised the importance of the characteristics of the encapsulated drug to the overall performance of liposomes as drug carriers [45].

Data presented in this work further support the assumption that physicochemical characteristics of encapsulated drug play an important role in the transport of the drug through the eye. Corneal absorption of the drug entrapped in the liposomes depends on its location within the liposomes, and this seems to be particularly disadvantageous for hydrophilic molecules which are located in the aqueous core of the liposome [45]. The liposomes prepared using conventional "film method" have shown significantly higher potential to deliver RbP into the cornea compared to the liposomes prepared using "polyol dilution method". However, these liposomes did not provide any permeability enhancement compared to the aqueous solution of the drug. 


\section{Conclusions}

This study was focused on the development of novel formulations of riboflavin and riboflavin-5'-phosphate for their efficient topical delivery to the eye to facilitate corneal cross-linking in the treatment of keratoconus. The permeability of these drugs into and through freshly excised bovine cornea was studied in vitro and it was found that drug diffusion is very slow, confirming the need for advanced formulations with enhanced drug permeability. It was established that riboflavin-5'-monophosphate is converted to riboflavin in the cornea and this process is mediated with enzymes present in this biological tissue. This finding has significant implications for detection of riboflavinmonophosphate in the permeability measurements and understanding of the processes and behavior of riboflavin-5'monophosphate in the cornea.

Six different liposomal formulations of riboflavin-5'-monophosphate were developed in this work and studied for their ability to facilitate drug permeability into the cornea. However, there was no statistically significant improvement in the penetration of riboflavin-5'-monophosphate into the cornea when the drug is encapsulated in the liposomes. These results might be explained by the hydrophilic nature of riboflavin-5'-monophosphate and are in agreement with several previous studies using other hydrophilic drugs.

\section{Conflict of interest}

The authors declare no conflict of interests. No animal or human studies were carried out by the authors for this article 


\section{References}

[1] Morrison PWJ, Khutoryanskiy VV. Enhancement in corneal permeability of riboflavin using calcium sequestering compounds. Int J Pharm 2014; 472(1-2): 56-64.

[2] Wollensak G, Spoerl E, Seiler T. Riboflavin/ultraviolet-a-induced collagen crosslinking for the treatment of keratoconus. Am J Ophthalmol 2003; 135(5): 620-627.

[3] Kamaev P, Friedman MD, Sherr E, Muller D. Photochemical Kinetics of Corneal Cross-Linking with Riboflavin. Investigative Ophthalmology \& Visual Science 2012; 53(4): 2360-2367.

[4] Dahl BJ, Spotts E, Truong JQ. Corneal collagen cross-linking: an introduction and literature review. Optometry 2012; 83(1): 33-42.

[5] Craig JA, Mahon J, Yellowlees A, Barata T, Glanville J, Arber M, Mandava L, Powell J, Figueiredo F. Epithelium-off photochemical corneal collagen cross-linkage using riboflavin and ultraviolet a for keratoconus and keratectasia: a systematic review and meta-analysis. Ocul Surf 2014; 12(3): 202-214.

[6] Morrison PWJ, Khutoryanskiy VV. Advances in ophthalmic drug delivery. Ther Deliv 2014; 5(12): 12971315.

[7] Morrison PWJ, Connon CJ, Khutoryanskiy VV. Cyclodextrin-mediated enhancement of riboflavin solubility and corneal permeability. Mol Pharm 2013; 10(2): 756-762.

[8] Bottos KM, Oliveira AG, Bersanetti PA, Nogueira RF, Lima-Filho AAS, Cardillo JA, Schor P, Chamon W. Corneal absorption of a new riboflavin-nanostructured system for transepithelial collagen cross-linking. PLoS One 2013; 8(6): e66408.

[9] Khutoryanskaya OV, Morrison PWJ, Seilkhanov SK, Mussin MN, Ozhmukhametova EK, Rakhypbekov TK, Khutoryanskiy VV. Hydrogen-bonded complexes and blends of poly(acrylic acid) and methylcellulose: Nanoparticles and mucoadhesive films for ocular delivery of riboflavin. Macromol Biosci 2014; 14(2): 225234.

[10] Lidich N, Wachtel EJ, Aserin A, Garti N. Water-Dilutable Microemulsions for Transepithelial Ocular Delivery of Riboflavin Phosphate. J Colloid Interface Sci 2016; 463: 342-348.

[11] Lamy R, Chan E, Zhang H, Salgaonkar VA, Good SD, Porco TC, Diederich CJ, Stewart JM. Ultrasoundenhanced penetration of topical riboflavin into the corneal stroma. Invest Ophthalmol Vis Sci 2013; 54(8): 5908-5912.

[12] O’Brart DPS. Corneal collagen cross-linking: a review. J Optom 2014; 7(3): 113-124.

[13] Mishra G, Bagui M, Tamboli V, Mitra A. Recent applications of liposomes in ophthalmic drug delivery. J Drug Deliv 2011; 2011, Article ID 863734.

[14] Kaur IP, Garg A, Singla AK, Aggarwal D. Vesicular systems in ocular drug delivery: an overview. Int J 
Pharm 2004; 269 (1): 1-14.

[15] Gaudana R, Ananthula HK, Parenky A, Mitra AK. Ocular drug delivery. AAPS J 2010; 12(3): 348-360.

[16] Benelli U. Systane lubricant eye drops in the management of ocular dryness. Clin Ophthalmol 2011; 5: 783790.

[17] Llamas-Moreno JF, Baiza-Durán LM, Saucedo-Rodríguez LR, Alaníz-De la O JF. Efficacy and safety of chondroitin sulfate/xanthan gum versus polyethylene glycol/propylene glycol/hydroxypropyl guar in patients with dry eye. Clin Ophthalmol 2013; 7: 995-999.

[18] Shen Y, Tu J. Preparation and ocular pharmacokinetics of ganciclovir liposomes. AAPS J 2007; 9(3): E371E377.

[19] Vanic Z, Hurler J. Novel vaginal drug delivery system: deformable propylene glycol liposomes-in-hydrogel. J Liposome Res 2013; 2104(1): 27-36.

[20] Mun EA, Morrison PWJ, Williams AC, Khutoryanskiy VV. On the barrier properties of the cornea: a microscopy study of the penetration of fluorescently labeled nanoparticles, polymers, and sodium fluorescein. Mol Pharm 2014; 11(10): 3556-3564.

[21] Anyakora C, Afolami I, Ehianeta T, Onwumere F. HPLC analysis of nicotinamide, pyridoxine, riboflavin and thiamin in some selected food products in Nigeria. African J Pharm Pharmacol 2008; 2(2): 29-36.

[22] Gadd AJR, Greco F, Cobb AJA, Edwards AD. Targeted Activation of Toll-Like Receptors: Conjugation of a Toll-Like Receptor 7 Agonist to a Monoclonal Antibody Maintains Antigen Binding and Specificity. Bioconj Chem 2015; 26 (8): 1743-17521.

[23] Fry DW, White JC, Goldman ID. Rapid separation of low molecular weight solutes from liposomes without dilution. Anal Biochem 1978; 90(2): 809-815.

[24] Bender R, Lange S. Adjusting for multiple testing - When and how? J Clin Epidemiol 2001; 54(4): 343-349.

[25] Pepić I, Lovrić J, Filipović-Grčić J. How do polymeric micelles cross epithelial barriers? Eur J Pharm Sci 2013; 50(1): 42-55.

[26] Lee VH, Robinson JR. Topical ocular drug delivery: recent developments and future challenges. J Ocul Pharmacol 1986; 2(1): 67-108.

[27] Grass GM, Robinson JR. Relationship of Chemical Structure to Corneal Penetration and Influence of LowViscosity Solution on Ocular Bioavailability. Am J Dig Dis 1984; 73(8): 1021-1027.

"www.chemicalize.org." [Online].

Available: http://www.chemicalize.org/structure/\#!mol=riboflavin\&source=calculate. [Accessed: 15-Aug-2015].

"www.chemicalize.org." [Online].

Available:

http://www.chemicalize.org/structure/\#!mol=riboflavin+5\%27-monophosphate\&source=calculate.

[Accessed: 15-Aug-2015]. 
[30] Prausnitz MR, Noonan JS. Permeability of cornea, sclera, and conjunctiva: A literature analysis for drug delivery to the eye. J Pharm Sci 1998; 87(12): 1479-1488.

[31] Rathore K, Nema R. An insight into ophthalmic drug delivery system. Int J Pharm Sci Drug Res 2009; 1(1): $1-5$.

[32] Lam FL, Lowande A. The simultaneous assay of riboflavin 5-phosphate sodium and other water-soluble vitamins in liquid multivitamin formulations by liquid chromatograph. J Pharm Biomed Anal 1988; 6(1): $87-95$.

[33] Beztsinna N, Tsvetkova Y, Bartneck M, Lammers T, Kiessling F, Bestel I. Amphiphilic phospholipid-based riboflavin derivatives for tumor targeting nanomedicines. Bioconj Chem 2016; 27(9): 2048-2061.

[34] Ahmad I, Arsalan A, Ali SA, Bano R, Munir I, Sabah A. Formulation and stabilization of riboflavin in liposomal preparations. J Photochem Photobiol B Biol 2015; 153: 358-366.

[35] Elmoslemany RM, Abdallah OY, El-Khordagui LK, Khalafallah NM. Propylene glycol liposomes as a topical delivery system for miconazole nitrate: comparison with conventional liposomes. AAPS PharmSciTech 2012; 13(2); 723-731.

[36] Wagner A, Vorauer-Uhl K. Liposome technology for industrial purposes. J Drug Deliv 2011; 2011: 591325.

[37] Verma D. Particle size of liposomes influences dermal delivery of substances into skin. Int J Pharm 2003; 258(1-2): 141-151.

[38] Yu S, Wang Q, Wang X, Liu D, Zhang W, Ye T, Yang X, Pan W. Liposome incorporated ion sensitive in situ gels for opthalmic delivery of timolol maleate. Int J Pharm 2015; 480(1-2): 128-136.

[39] Lin D-Q, Brixius PJ, Hubbuch JJ, Thömmes J, Kula M-R. Biomass/adsorbent electrostatic interactions in expanded bed adsorption: a zeta potential study. Biotechnol Bioeng 2003; 83(2): 149-157.

[40] Li D, Müller MB, Gilje S, Kaner RB, Wallace GG. Processable aqueous dispersions of graphene nanosheets. Nat Nanotechnol 2008; 3(2): 101-105.

[41] Palac Z, Engesland A, Flaten GE, Škalko-Basnet N, Filipović-Grčić J, Vanić Ž. Liposomes for (trans)dermal drug delivery: the skin-PVPA as a novel in vitro stratum corneum model in formulation development. $\mathrm{J}$ Liposome Res 2014; 24(4): 313-322.

[42] Meisner D, Mezei M. Liposome ocular delivery systems. Advanced Drug Delivery Reviews 1995; vol. 16, no. 1. pp. 75-93, 1995.

[43] Vanic Z, Hafner A, Bego M, Škalko-Basnet N. Characterization of various deformable liposomes with metronidazole. Drug Dev Ind Pharm 2013; 39(3): 481-488.

[44] Pavelić Ž, Škalko-Basnet N, Schubert R. Liposomal gels for vaginal drug delivery. Int J Pharm 2001; 219(1-2): 139-149.

[45] Singh K, Mezei M. Liposomal ophthalmic drug delivery system. II. Dihydrostreptomycin sulfate. Int J 
Pharm 1984; 19(3): 263-269. 


\section{Legends to figures}

Fig. 1. Schematic illustration of corneal cross-linking (CXL) treatment of keratoconus: (a) intact cornea; (b) cornea with physically removed epithelium; (c) topical application of RbP on de-epithelialized cornea; (d) irradiation of cornea saturated with RbP by UVA; (e) additionally cross-linked cornea with improved mechanical properties.

Fig. 2 (A) Total drug penetrated into the cornea calculated from the difference in the concentration in FDC donor chamber before and after three hours exposure to bovine cornea. ${ }^{*} p<0.05$, Student's t-test, $\mathrm{n}=3$. (B) Amount of $\mathrm{Rb}$ and $\mathrm{RbP}$ extracted from the cornea after three hours of in vitro penetration experiment. $p>0.05$, Student's t-test, $\mathrm{n}=3$.

Fig. 3. Overlaid HPLC chromatograms for RbP from the experiment with the homogenized cornea. The typical chromatogram for RbP shows two peaks. The RbP peak appeared after $1.8 \mathrm{~min}$ and the $\mathrm{Rb}$ peak was found to have retention time of $5.3 \mathrm{~min}$. The red curve represents the measurement at time zero. The blue curve shows the change in concentrations after 2 hours exposure to homogenized cornea at $37^{\circ} \mathrm{C}$. Insert: Scheme of RbP conversion into $\mathrm{Rb}$

Fig. 4. Entrapment efficacy of RbP in various liposomal formulations. FM, film method; PD, polyol dilution method; EPC, egg phosphatidylcholine; S75, soybean lecithin with $70 \%$ phosphatidylcholine; S100, soybean lecithin, $>94 \%$ phosphatidylcholine. ${ }^{*} p<0.05,{ }^{* *} p<0.01$, One way ANOVA followed by a Bonferroni post hoc test, $\mathrm{n}=3$.

Fig. 5. Amount of RbP extracted from the bovine corneas treated with different liposomal formulations compared to $\mathrm{RbP}$ aqueous solution at $10 \mathrm{mg} / \mathrm{mL} .{ }^{*} p<0.05$, Student's t-test, $\mathrm{n}=3$. FM, film method; PD, polyol dilution method; EPC, egg phosphatidylcholine 


\title{
Supplementary Information
}

Delivery of riboflavin-5'-monophosphate into the cornea:

can liposomes provide any enhancement effects?

\author{
Neva Kandzija, Vitaliy V. Khutoryanskiy*
}

Reading School of Pharmacy, University of Reading, Reading, Berkshire, RG6 6AD, UK

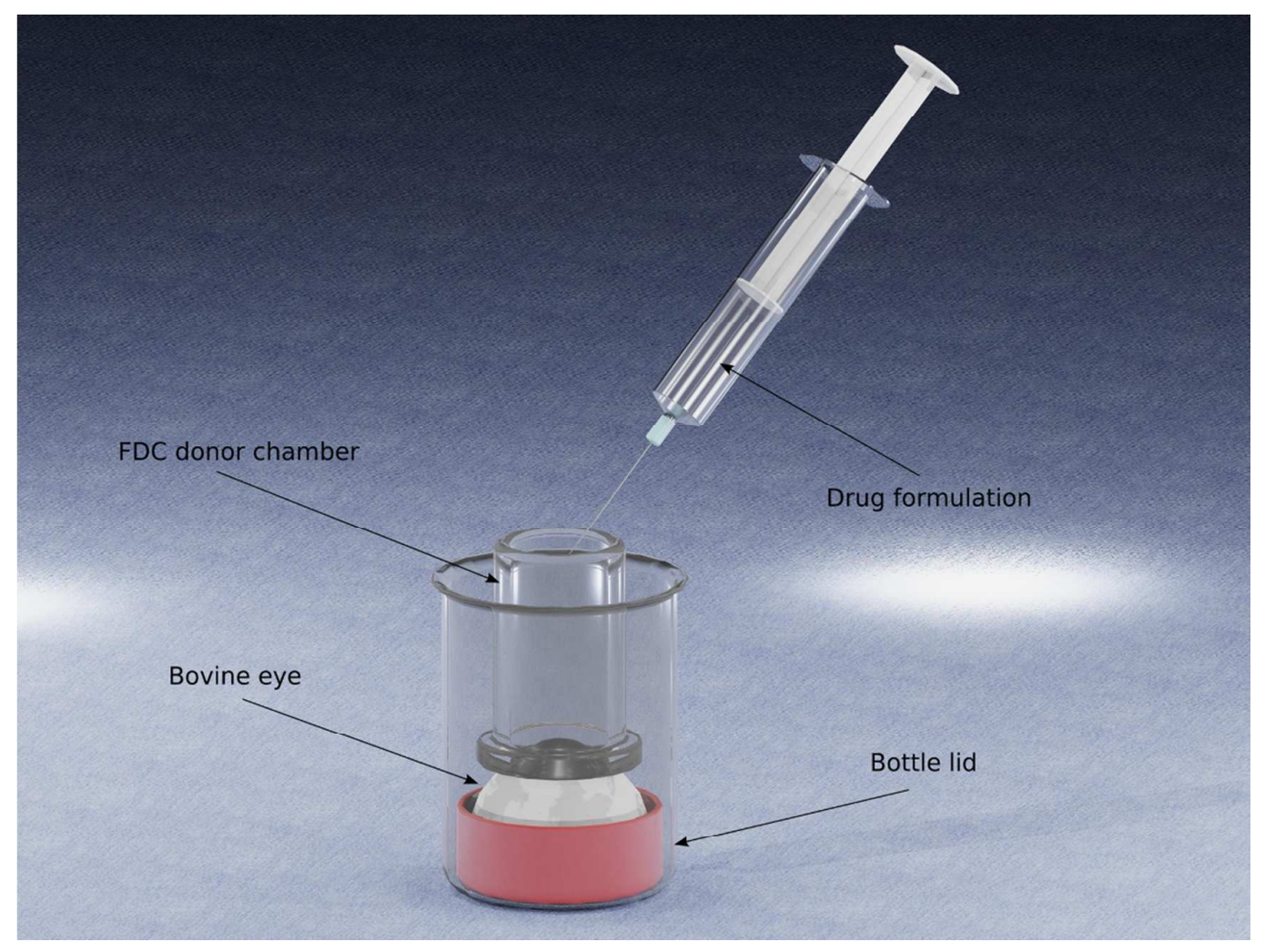

Fig 1s. Whole eye method for studying drug in vitro penetration. 


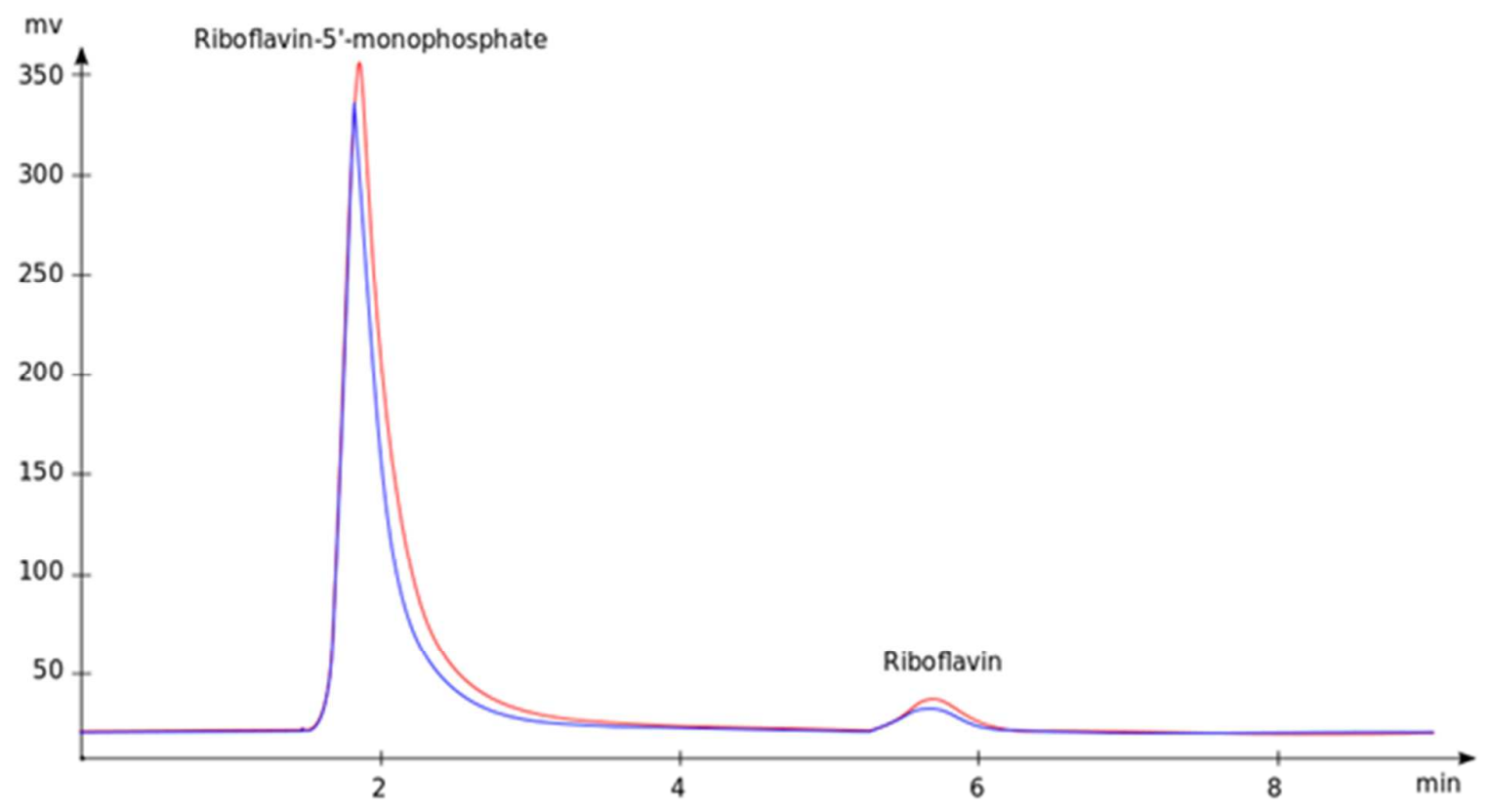

Fig. 2s Overlaid HPLC chromatograms for RbP from the experiment with autoclaved homogenized cornea and schematic representation of the conversion of $\mathrm{RbP}$ into $\mathrm{Rb}$. The chromatogram for RbP shows two peaks. The $\mathrm{RbP}$ peak appeared after $1.8 \mathrm{~min}$ and the $\mathrm{Rb}$ peak was found to have retention time of $5.3 \mathrm{~min}$. The red curve represents measurement at time zero. The blue curve shows the change in concentrations after 2 hours exposure to homogenized cornea previously autoclaved.

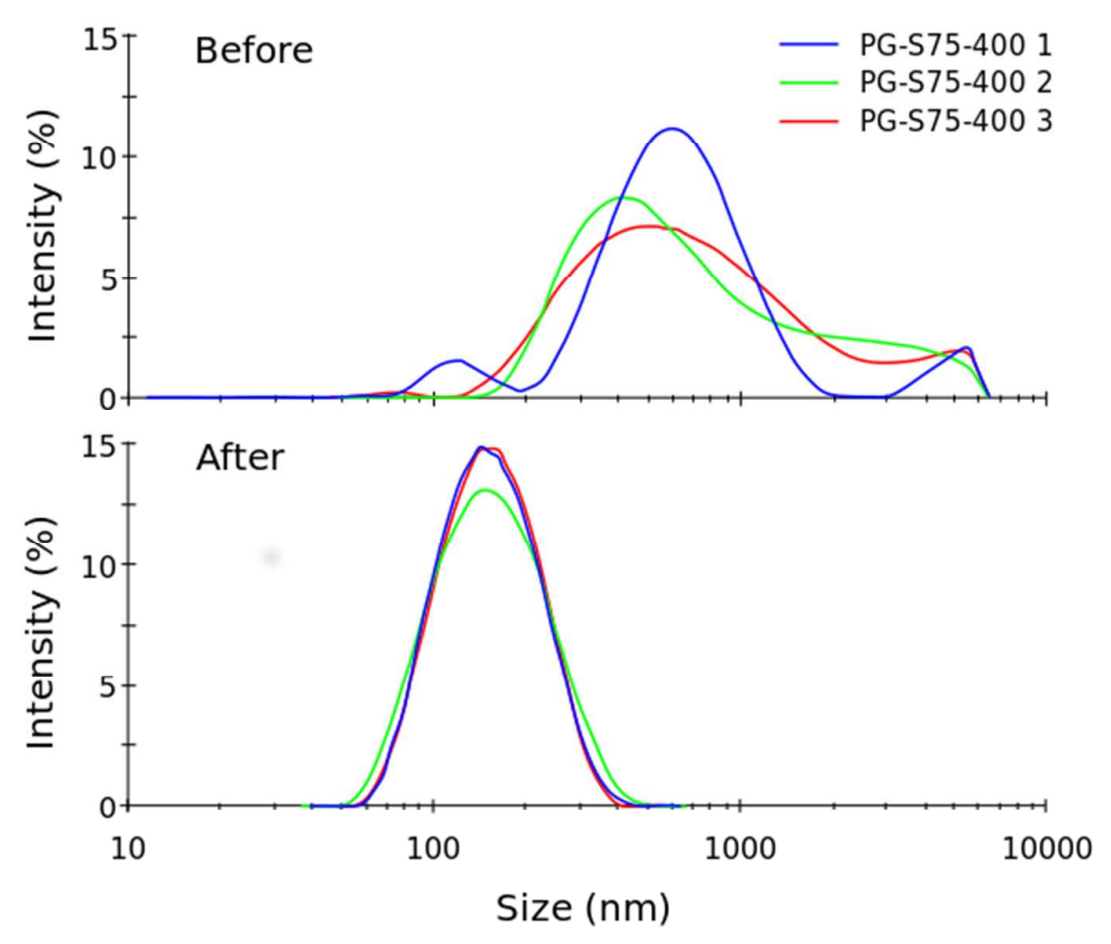

Fig. 3s Dynamic light scattering size distributions of liposomal preparation (PG-S75-400) before and after the size reduction performed by extrusion through 200-nm membrane 


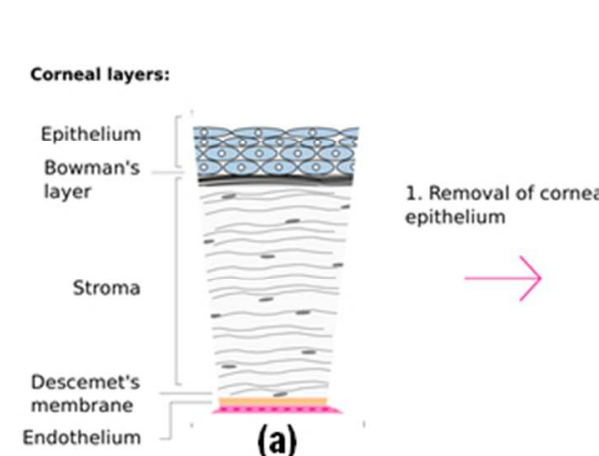

(a)

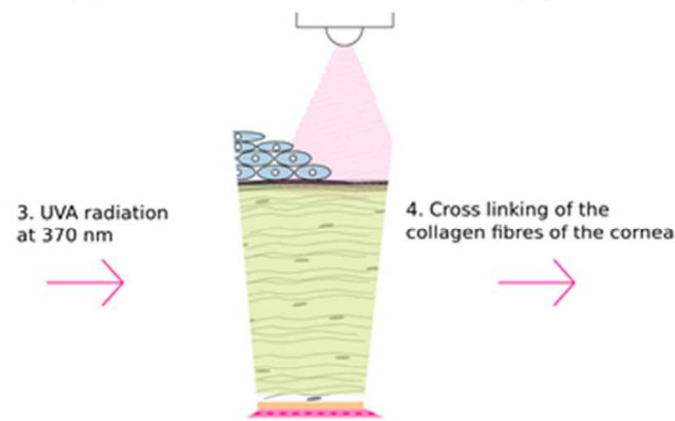

(d)

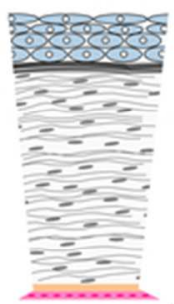

(e)

Fig. 1. Schematic illustration of corneal cross-linking (CXL) treatment of keratoconus: (a) intact cornea; (b) cornea with physically removed epithelium; (c) topical application of RbP on de-epithelialized cornea; (d) irradiation of cornea saturated with RbP by UVA; (e) additionally cross-linked cornea with improved mechanical properties.

$180 \times 133 \mathrm{~mm}(96 \times 96$ DPI) 
A)

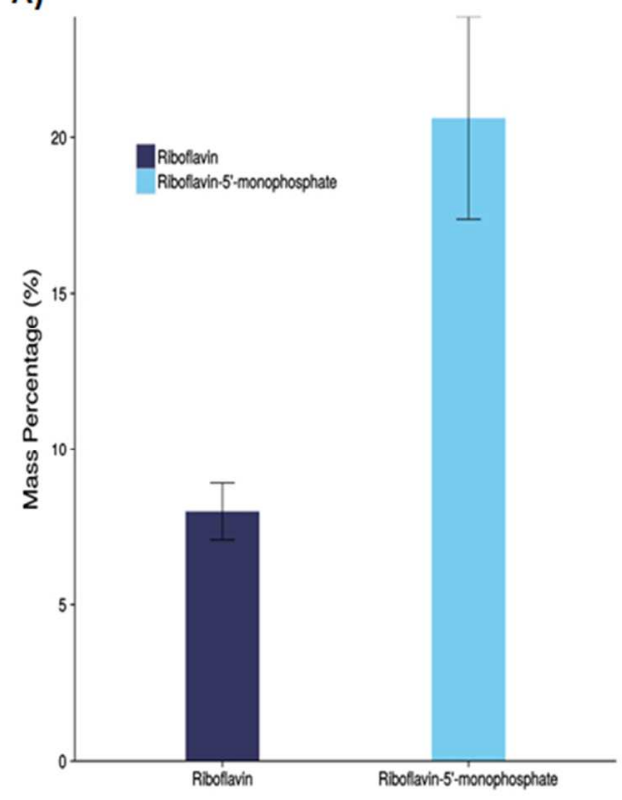

B)

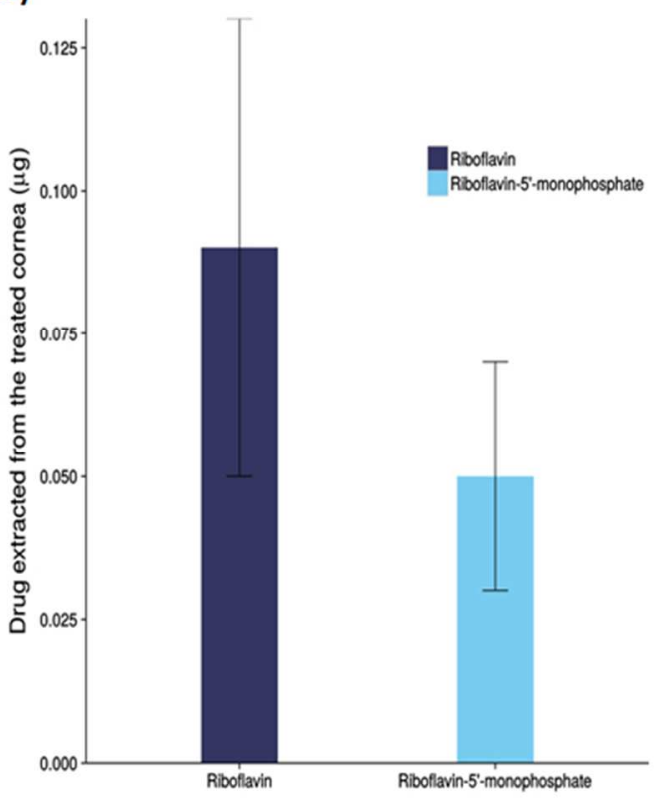

Fig. 2 (A) Total drug penetrated into the cornea calculated from the difference in the concentration in FDC donor chamber before and after three hours exposure to bovine cornea. ${ }^{*} p<0.05$, Student's t-test, $n=3$. (B) Amount of $\mathrm{Rb}$ and $\mathrm{RbP}$ extracted from the cornea after three hours of in vitro penetration experiment. $p>0.05$, Student's t-test, $n=3$. 


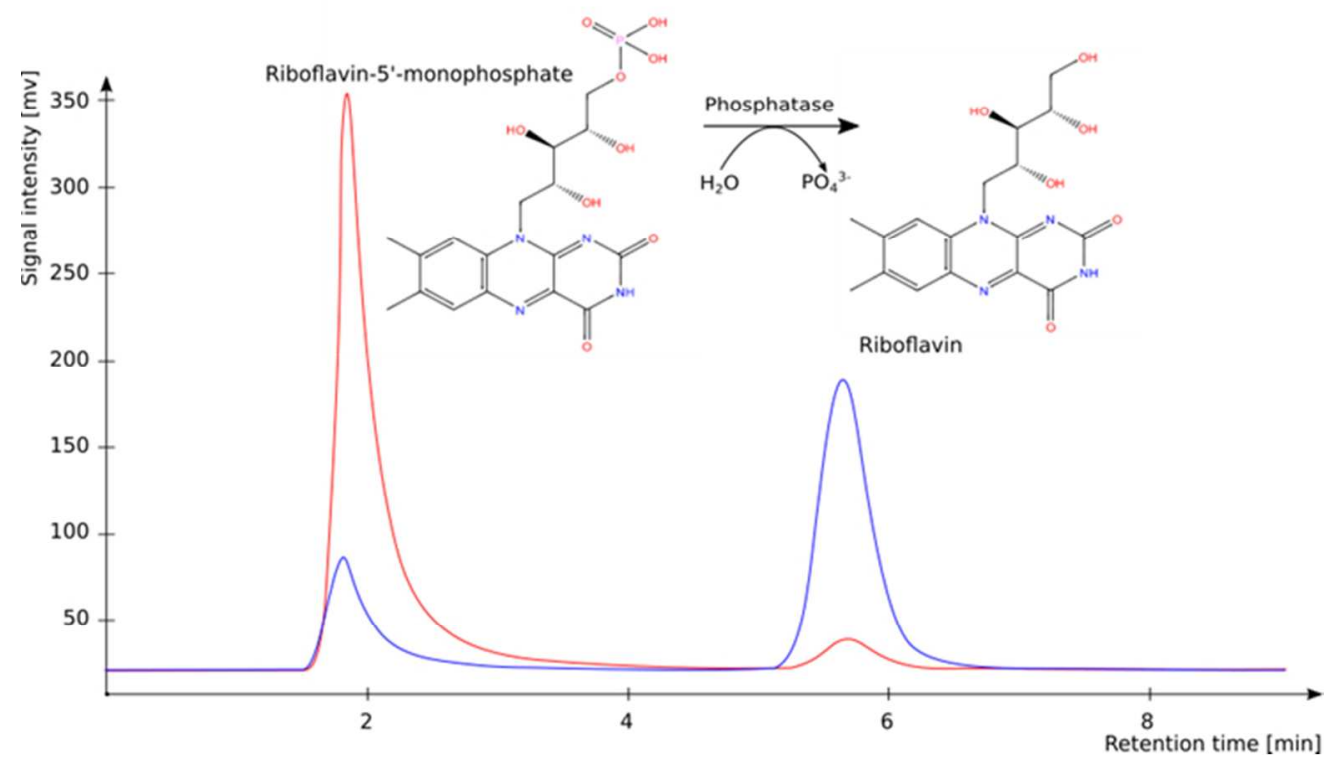

Fig. 3. Overlaid HPLC chromatograms for RbP from the experiment with the homogenized cornea. The typical chromatogram for RbP shows two peaks. The RbP peak appeared after 1.8 min and the Rb peak was found to have retention time of $5.3 \mathrm{~min}$. The red curve represents the measurement at time zero. The blue curve shows the change in concentrations after 2 hours exposure to homogenized cornea at $37^{\circ} \mathrm{C}$. Insert: Scheme of RbP conversion into $\mathrm{Rb}$

$194 \times 115 \mathrm{~mm}(96 \times 96 \mathrm{DPI})$ 


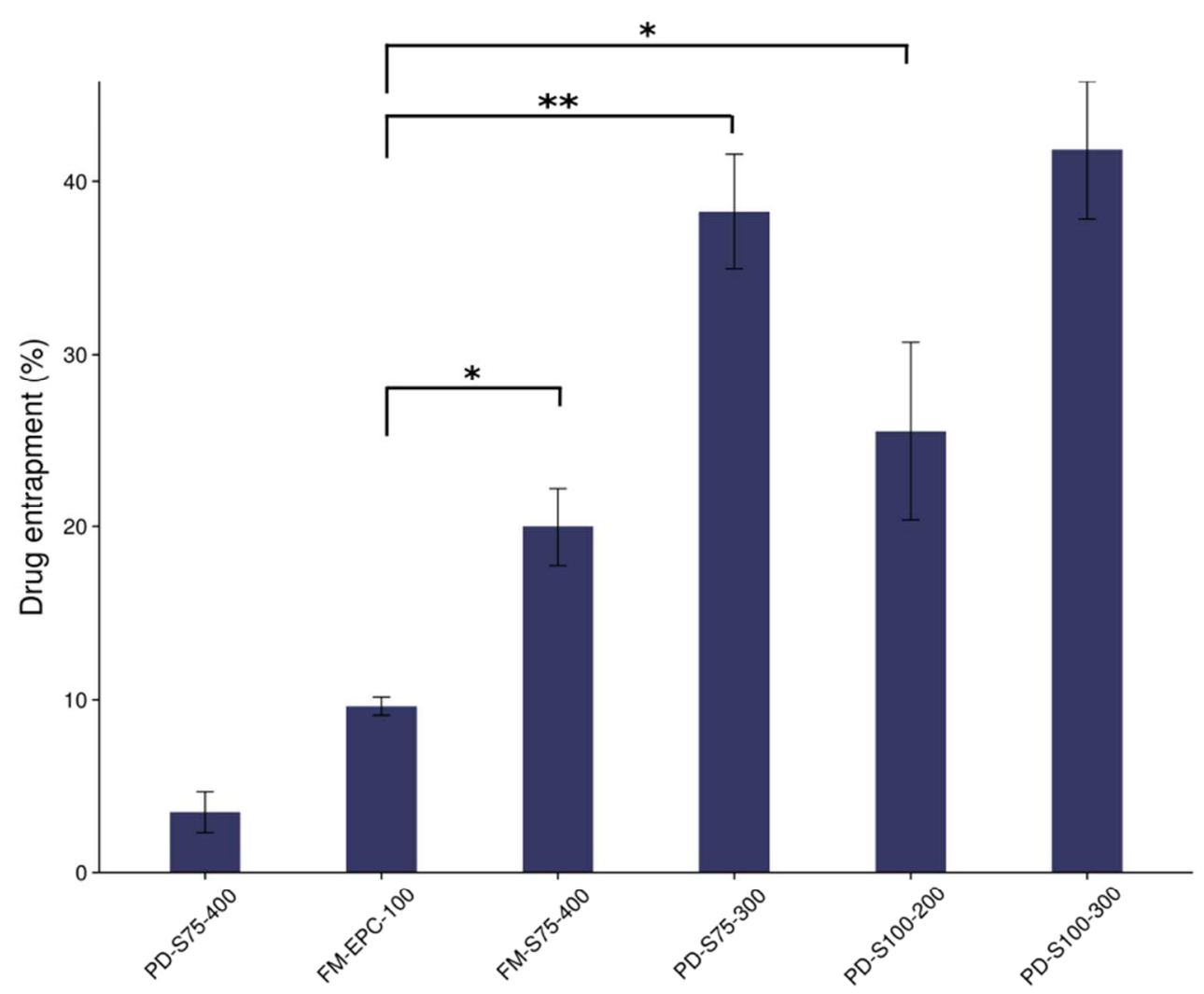

Fig. 4. Entrapment efficacy of RbP in various liposomal formulations. FM, film method; PD, polyol dilution method; EPC, egg phosphatidylcholine; S75, soybean lecithin with $70 \%$ phosphatidylcholine; S100, soybean lecithin, $>94 \%$ phosphatidylcholine. $* p<0.05, * * p<0.01$, One way ANOVA followed by a Bonferroni post hoc test, $\mathrm{n}=3$.

$243 \times 204 \mathrm{~mm}(96 \times 96 \mathrm{DPI})$ 


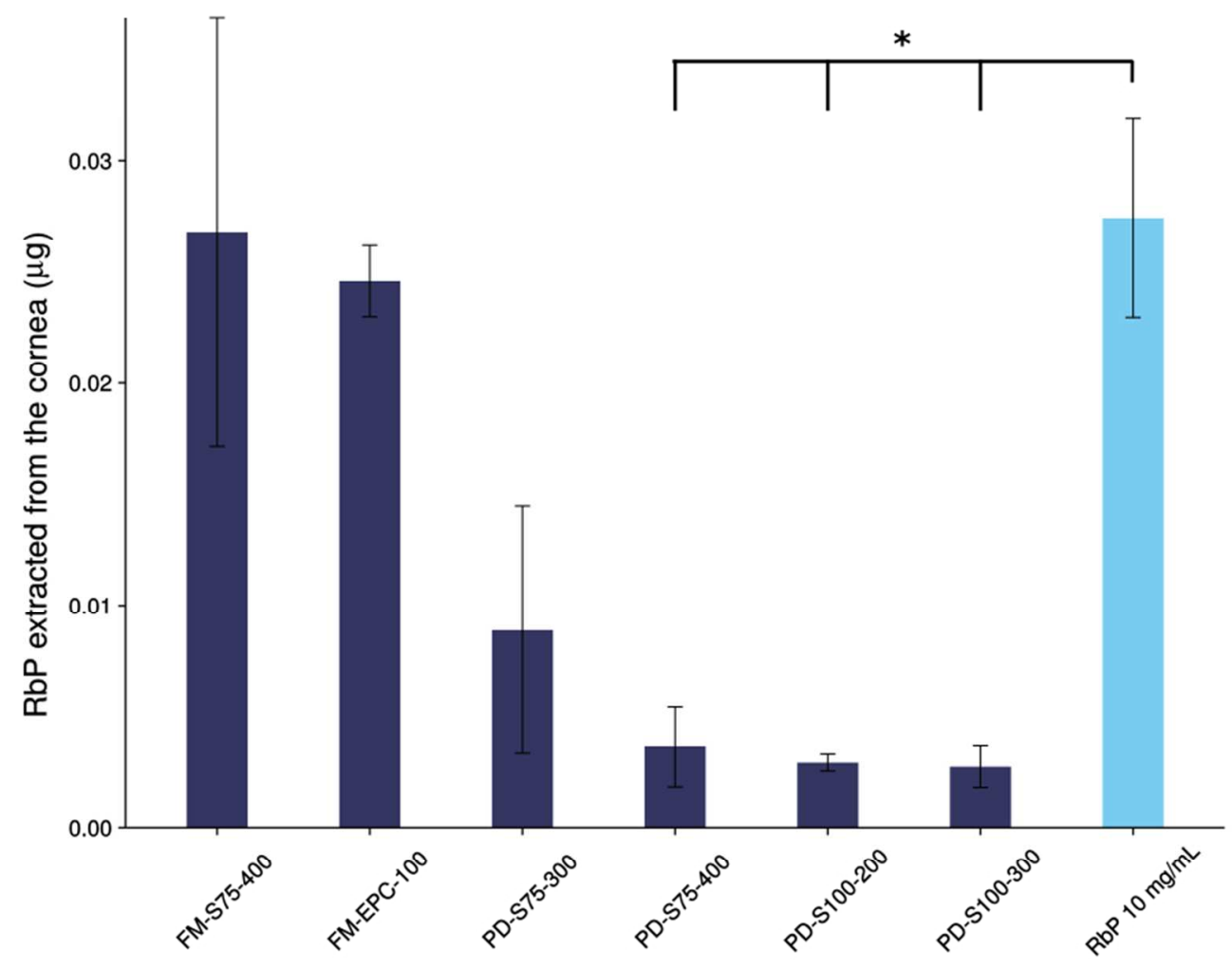

Fig. 5. Amount of RbP extracted from the bovine corneas treated with different liposomal formulations compared to RbP aqueous solution at $10 \mathrm{mg} / \mathrm{mL}$. ${ }^{*} \mathrm{p}<0.05$, Student's t-test, $\mathrm{n}=3$. FM, film method; $\mathrm{PD}$, polyol dilution method; EPC, egg phosphatidylcholine

$254 \times 203 \mathrm{~mm}(90 \times 90 \mathrm{DPI})$ 
Table 1. Composition and physicochemical properties of different liposomal formulations containing RbP. The total volume of liposomal suspensions was kept the same $(5 \mathrm{~mL})$ in all preparations.

\begin{tabular}{|c|c|c|c|c|c|c|c|c|c|c|}
\hline \multirow{2}{*}{$\begin{array}{r}\text { Sample } \\
\text { Code }\end{array}$} & \multirow{2}{*}{$\begin{array}{l}\mathbf{S 1 0 0} \\
(\mathrm{mg})\end{array}$} & \multirow{2}{*}{$\begin{array}{l}\text { S75 } \\
(\mathrm{mg})\end{array}$} & \multirow{2}{*}{$\begin{array}{l}\text { EPC } \\
(\mathrm{mg})\end{array}$} & \multirow{2}{*}{$\begin{array}{l}\text { PG } \\
\text { (g) }\end{array}$} & \multirow{2}{*}{$\begin{array}{l}\mathbf{R b P} \\
(\mathrm{mg})\end{array}$} & \multicolumn{2}{|c|}{ Mean Diameter (nm) } & \multicolumn{2}{|c|}{ Polydispersity Index } & \multirow{2}{*}{$\begin{array}{c}\text { Zeta } \\
\text { Potential } \\
(\mathrm{mV})\end{array}$} \\
\hline & & & & & & Before extr. & After extr. & Before extr. & After extr. & \\
\hline $\begin{array}{l}\text { FM-S75- } \\
400\end{array}$ & 0 & 400 & 0 & 0 & 10 & $6836 \pm 1602$ & $189 \pm 1$ & $0.399 \pm 0.129$ & $0.217 \pm 0.005$ & $-47.5 \pm 1.5$ \\
\hline $\begin{array}{l}\text { FM-EPC- } \\
100\end{array}$ & 0 & 0 & 100 & 0 & 10 & $2156 \pm 345$ & $187 \pm 1$ & $0.686 \pm 0.389$ & $0.170 \pm 0.009$ & $-15.1 \pm 0.4$ \\
\hline PD-S75-300 & 0 & 300 & 0 & 1 & 10 & $540 \pm 9$ & $142 \pm 1$ & $0.371 \pm 0.015$ & $0.121 \pm 0.003$ & $-24.8 \pm 0.5$ \\
\hline PD-S75-400 & 0 & 400 & 0 & 1 & 10 & $496 \pm 13$ & $142 \pm 1$ & $0.388 \pm 0.033$ & $0.120 \pm 0.012$ & $-26.2 \pm 0.6$ \\
\hline $\begin{array}{l}\text { PD-S100- } \\
200\end{array}$ & 200 & 0 & 0 & 1 & 10 & $1838 \pm 184$ & $126 \pm 1$ & $1.000 \pm 0.000$ & $0.167 \pm 0.008$ & $-3.4 \pm 0.3$ \\
\hline $\begin{array}{l}\text { PD-S100- } \\
300\end{array}$ & 300 & 0 & 0 & 1 & 10 & $1139 \pm 121$ & $132 \pm 1$ & $0.171 \pm 0.096$ & $0.173 \pm 0.007$ & $-3.6 \pm 0.3$ \\
\hline
\end{tabular}

PDI, polydispersity index; FM, film method; PD, polyol dilution method; EPC, egg phosphatidylcholine; S75, soybean lecithin with $70 \%$ phosphatidylcholine; S100, soybean lecithin, $>94 \%$ phosphatidylcholine.

Values shown are the mean \pm standard deviation of three repeats. Note that some of the formulations have very high polydispersity index, which means that they are highly polydisperse and their real sizes could be different from the data determined using dynamic light scattering. 